\title{
REDUCTION OPERATOR ALGEBRAS AND GENERALIZED SIMILARITY PROBLEM
}

\author{
RACHID EL HARTI
}

\begin{abstract}
In this paper, we give new results on reduction operator algebras. We investigate the relationship between the generalized similarity problem and the total reduction property. We also give some sufficient and necessary conditions for a reduction operator algebra to be self-adjoint or similar to a $\mathrm{C}^{*}$-algebra.
\end{abstract}

Mathematics subject classification (2010): 46L07, 46L05, 47L55, 47A15.

Keywords and phrases: operator algebras; similarity problems; total reduction property.

\section{REFERENCES}

[1] A. Connes, On the Cohomology operator algebras, J. Funct. Anal., 28 (1978), 248-253.

[2] J. B. ConwaY, A cours in Operator Theory, Graduate students in Mathematics, Vol 21, Amer. Math. Soc. Providence, Rhode Island.

[3] P. C. Curtis, JR And R. J. Loy, The structure of amenable Banach algebras, Proc. London. Math. Soc., 40, 2 (1989), 89-104.

[4] P. C. CURTIS, JR AND R. J. LoY, A note on amenable algebras of operators, Bull. Austral. Math. Soc., 52 (1995) 327-329.

[5] P.G. Dixon, Approximate identities in normed algebras, Proc. Lond. Math. Soc., 26, 3 (1973) 485496.

[6] R. El HaRTI, The structure of a subclass of amenable operator algebra, International J. Math. Math. Soc., 55, (2004) 2963-2969.

[7] J. E. Galé, T. J. RANSFord And M. C. While, Weakly compact homomorphisms, Trans. Amer. Math. Soc., 331, 2 (1992) 815-824.

[8] J. A. GifForD, Operator algebras with a reduction property, Ph. D thesis, Australian National university, 1997.

[9] J. A. GIFFORD, Operator algebras with a reduction property, J. Aust. Math. Soc., 80 (2006), 297-315.

[10] F. Ghahramani, R. J. LOY AND G. A. Willis, Amenability and weak amenability of second conjugate Banach algebras, Proc. Amer. Math. Soc., 124 (1996), 1489-1497.

[11] U. HAAGERUP, All nuclear $C^{*}$-algebras are amenable, Invent. Math., 74 (1983), 305-319.

[12] U. HaAgeruP, Solution of similarity problem, for cyclic representation of $C^{*}$-algebras, Ann. of Math., 118 (1983) 215-240.

[13] B. E. Jhonson, Cohomolgy in Banach algebras, Mem. Amer. Math. Soc., 127 (1971).

[14] B. E. JHonson, Approximate diagonals and Cohomology of certain annihilator Banach algebras, Amer. J. Math., 94 (1972) 685-698.

[15] R. KADISOn, On the orthogonalization of operator representations, Amer. J. Math., 77 (1955) 600620.

[16] M. Radjavi And P. Rosenthal, A sufficient condition that an operator algebra be self-adjoint, Can. J. Math., XXIII, 4, (1971) 588-597.

[17] V. PAUlsen, Completely bounded maps and operator algebras, Cambridge Students in Advanced Mathematics, 78. Cambridge university Press.

[18] G. PISIER, A polynomially bounded operator on Hilbert space which is not similar to a contraction, J. Amer. Math. Soc., 10 (1997) 351-369. 
[19] G. PISIER, Similarity problems and completely bounded maps, Lecture Notes in Math, 1681, Second Edition, Springer-Verlag, 2001.

[20] G. PISIER, Similarity problem and lenght, Taiwanese J. Math., 5, 1 (2001), 1-17.

[21] D. PITTS, Norming algebras and automatic complete boundedness of isomorphisms of operator algebras, Proc. Amer. Math. Soc., 136, 5, (2008) 1757-1768. 